\title{
Crédito, crisis y cambio institucional en una economía virreinal. Salta ante el reformismo borbónico, 1777-1786
}

\author{
Martín Leandro Ezequiel Wasserman* \\ Marcelo Gabriel Anachuri**
}

Recibido el 7 de mayo de 2019; aceptado el 11 de julio de 2019

\section{RESUMEN}

Desde que la historiografía reconoció a la Real Hacienda como materialización institucional y financiera de la Monarquía católica, fue viable comprender que la dinámica del Hispanus fiscus conjugaba la tensión y la negociación entre las instancias centrales y locales de poder, antes que un edificio piramidal con cadenas de mando verticalmente direccionadas como la normativa lo procuraba. Ello permitió matizar el modelo coercitivo y centralizado de la organización imperial borbónica en el campo fiscal, pero resta ahondar en las implicancias que estos límites y alcances del centralismo borbónico tuvieron en el desempeño de la interacción comercial. Las prácticas crediticias constituyen, en este sentido, una atalaya desde la cual observar los efectos que la política borbónica tuvo sobre la economía local y regional en Hispanoamérica. El crédito es, así, una ventana para indagar sobre el impacto que las modulaciones institucionales ejercieron sobre el desempeño económico en el Antiguo Régimen hispanoamericano.

* Universidad de Buenos Aires-Consejo Nacional de Investigaciones Científicas y Técnicas, Buenos Aires, Argentina. Correo electrónico: martinwasserman@hotmail.com. ORCID: https://orcid.org/0000-0001-9414-7449

** Universidad Nacional de Salta, Salta, Argentina. Correo electrónico: gabrielanachuri2016@gmail.com. .ORCID: https://orcid.org/0000-0002-4127-2665 
El presente artículo se propone como principal objetivo indagar el impacto que las reformas borbónicas pudieron tener sobre la economía comercial en Hispanoamérica, mediante una lectura estadística y relacional del crédito escriturado notarialmente en Salta, uno de los más importantes nodos comerciales del Virreinato del Río de la Plata.

En este sentido, se concluye que el cambio institucional implicado en el establecimiento de la Intendencia de Salta del Tucumán (1784), sin haber subsumido fiscalmente la región salteña al epicentro rioplatense - tal como lo procuraba una política de centralización hacendaria—, fomentó la integración comercial entre Salta y otras plazas mercantiles regionales como modo de superar la crisis derivada de los cortocircuitos en el comercio interregional generados por los levantamientos andinos de la década de 1780 .

Desde hace ya más de dos décadas, la historiografía hispanoamericana logró explicar de manera concluyente que el crédito escriturado notarialmente sirvió, durante los siglos XVII y XVIII, para articular circuitos comerciales de larga distancia y enlazar nodos mercantiles. Ratificando las hipótesis de aquella historiografía, este artículo ahonda en aquellas interrogantes mediante una reconstrucción anual de los movimientos crediticios durante la década que corre entre 1777 y 1786, apelando a herramientas metodológicas procedentes tanto de la estadística como del Análisis de Redes Sociales, previamente subutilizadas. Ello permitirá comprender la incidencia del cambio institucional sobre una economía de Antiguo Régimen, focalizando en la dimensión relacional del crédito y en la estructura comercial a la cual éste sostenía y expresaba. Las fuentes empleadas para este abordaje consisten en las escrituras de obligación rubricadas por el escribano de Salta durante dicho período.

Palabras clave: Intendencias, siglo XVIII, Hispanoamérica, economía, comercio, crédito.

\title{
Credit, crisis and institutional change in a viceregal economy. Salta and the Bourbon reformism, 1777-1786
}

\begin{abstract}
Since historiography recognized the Royal Treasury as an institutional and financial materialization of the Catholic Monarchy, it was feasible to understand that the dynamics of Hispanus fiscus combined tension and negotiation between central and local instances of power, rather than a pyramidal structure verticallu commanded. This allowed to discuss the coercive and centralized model of the Bourbon imperial organization in the fiscal field, but it remains to delve into the implications that these limits of
\end{abstract}


the Bourbon centralism had on the performance of commercial interaction. Credit practices constitute, in this sense, a window to observe the effects that Bourbon politics had on the local and regional economy in Spanish America. The research on credit is, thus, way to investigate the impact that the institutional modulations exerted on the economic performance in the Old Spanish-American Regime.

The main objective of this article consists in investigate the impact that the Bourbon reforms could have on the commercial economy in Hispanic America, through a statistical and relational reading of the notarized credit in Salta, one of the most important commercial nodes of the Viceroyalty of Río de la Plata.

In this sense, the present work concludes that the institutional change implied in the establishment of the Intendancy of Salta del Tucumán (1784), even when could not achieve the fiscally subsumption of the Salta region to the rioplatense epicenter - as it was projected by a centralization fiscal policy - encouraged the commercial integration between Salta and other regional markets as a way to overcome the crisis derived from breakdowns in interregional trade generated by the Andean uprisings of the 1780s.

For more than two decades, Hispanic American historiography managed to explain that notarized credit served, during the seventeenth and eighteenth centuries, to articulate long-distance commercial circuits and linking mercantile nodes. Ratifying the hypothesis of that historiography, this article delves into those questions through an annual reconstruction of credit movements during the decade that runs between 1777 and 1786, appealing to methodological tools from both statistics and social network analysis, previously underutilized. This will make it possible to understand the impact of institutional change on an Old Regime economy, focusing on the relational dimension of credit and the commercial structure to which it maintained and to which it expressed. The sources used for this approach consist of the deeds of obligation signed by the scribe of Salta during the period.

Key words: Intendencies, XVIIIth century, Hispanic America, economy, commerce, credit.

\section{INTRODUCCIÓN}

$\mathrm{D}$ esde que la historiografía reconoció a la Real Hacienda como materialización institucional y financiera de la Monarquía católica, fue viable comprender que la dinámica del Hispanus fiscus conjugaba la tensión y la 
negociación entre las instancias centrales y locales de poder, antes que un edificio piramidal con cadenas de mando verticalmente direccionadas como la normativa lo procuraba. ${ }^{1}$ Ello permitió matizar el modelo coercitivo y centralizado de la organización imperial borbónica en el campo fiscal, pero resta ahondar en las implicancias que estos límites y alcances del centralismo borbónico tuvieron en el desempeño de la interacción comercial. ${ }^{2}$ Las prácticas crediticias constituyen, en este sentido, una atalaya desde la cual observar los efectos que la política borbónica tuvo sobre la economía local y regional en Hispanoamérica. El crédito es, así, una ventana para indagar sobre el impacto que las modulaciones institucionales ejercieron sobre el desempeño económico en el Antiguo Régimen hispanoamericano.

Hace ya más de dos décadas, el esclarecedor trabajo de Sara Mata ${ }^{3}$ explicó de manera concluyente que el crédito notarial permite comprender el rol económico de Salta durante la segunda mitad del siglo XVIII como un nodo articulador de circuitos comerciales, en los que el mercado mular constituía un engranaje fundamental. En este sentido, los actores económicos de Salta durante la segunda mitad del siglo XVIII apelaron a esas prácticas crediticias para desplegar sus transacciones comerciales, dando lugar a una estructuración regional de la economía. ${ }^{4}$

Ratificando sus hipótesis, este artículo se propone ahondar en interrogantes sobre los cuales el crédito notarial salteño también puede arrojar luz: la incidencia que sobre la economía local tuvieron las rebeliones andinas iniciadas en 1780 y el cambio institucional implicado en el establecimiento de la Intendencia de Salta del Tucumán. Para ello, volvemos a acceder a la información provista por el crédito notarial desde una reconstrucción anual de los movimientos crediticios durante la década que corre entre 1777 y 1786, apelando a herramientas metodológicas procedentes tanto de la estadística como del Análisis de Redes Sociales. Ello permitirá comprender la

1 Sobre la Real Hacienda como Hispanus fiscus véase Clavero, "Hispanus fiscus, persona ficta”; Sánchez Santiró "El orden jurídico de la fiscalidad en la Real Hacienda de Nueva España”.

2 Sobre la maquinaria fiscal de base redistributiva, que matizaba las virtudes centralizadoras tradicionalmente atribuidas al reformismo borbónico, véase Grafe \& Irigoin, "Bargaining for Absolutism”, en donde se postula la noción de absolutismo negociado para caracterizar institucionalmente a los mecanismos que operaban en la base del esquema fiscal imperial durante el siglo XVIII. Una aproximación al proyecto borbónico en materia hacendaria, y a sus contrastes con la implementación efectiva, puede observarse en Torres Sánchez, “Tejiendo una Hacienda Imperial”.

3 Mata, S., "El crédito mercantil. Salta a fines del siglo XVIII”, passim.

4 Sobre los procesos de integración regional, véase el ineludible trabajo de Assadourian, El sistema de la economía colonial. El mercado interior. Regiones y espacio económico; sobre el proceso de desintegración, Schmit e Irigoin, La desintegración de la economía colonial: comercio y moneda en el interior del espacio colonial, 1800-1860. 
incidencia del cambio institucional sobre una economía de Antiguo Régimen, focalizando en la dimensión relacional del crédito y en la estructura comercial a la cual éste sostenía, toda vez que para evaluar el impacto institucional de las reformas borbónicas en la economía hispanoamericana debe atenderse no sólo a las disposiciones normativas que alteraron el esquema con el cual el Erario procuraba gobernar sus finanzas, sino también a las modulaciones en la organización de la interacción económica, ya que los enlaces que sostenían al intercambio expresaban igualmente instituciones no visibilizadas en la normativa jurídica, pero operantes ante coyunturas cambiantes. ${ }^{5}$ La hipótesis que orienta al presente trabajo sugiere, por lo tanto, que si el establecimiento de la Intendencia de Salta de Tucumán es una de las más resaltantes expresiones del reformismo borbónico, sus efectos son disímiles en las diferentes instancias de la economía: aun cuando esta medida no logró centralizar plenamente la extracción de excedentes fiscales salteños, favoreció la integración de la economía salteña con el frente atlántico abierto en Buenos Aires (y con los mercados que anudaban el rosario interregional hasta el Río de la Plata, tal como lo demuestran los intercambios apoyados en el crédito). Aquellos límites en el incremento de la centralización de excedentes fiscales locales pudieron constituir el costo de una mayor integración comercial orientada al Atlántico.

\section{COYUNTURAS BORBÓNICAS: 1777-1786}

Durante los primeros años de la década de 1780, dos procesos de naturaleza diversa signaron a la economía de Salta: los levantamientos andinos y el establecimiento de la Intendencia de Salta del Tucumán.

En noviembre de 1780, una revolución estalla en Tungasuca. Con José Gabriel Condorcanqui (Túpac Amaru) a la cabeza, el movimiento rápidamente se expande más allá de Cuzco, replicándose de la mano de Tomás Catari y Túpac Catari. El suceso tendría implicancias económicas no sólo para la economía salteña, sino a escala virreinal: en enero de 1781, poco antes del cercamiento de La Paz, desde Buenos Aires el superintendente ordenaba a las Reales Cajas de Potosí, Chucuito, La Plata y Jujuy que entregasen caudales para sostener tanto a las tropas de Ignacio Flores como a

5 En este sentido, los arreglos institucionales con los que es estructurada la organización del intercambio para afrontar los riesgos de oportunismo o de información asimétrica y disminuir los costos implicados en dichos riesgos, pueden variar en un arco que alcanza formalizaciones heterogéneas: desde los contratos jurídicamente validados hasta la confianza interpersonal en las contrapartes o en los mediadores. Sobre la organización de la interacción económica como institución, véase Hodgson,“What are Institutions?”. 
cuatro compañías formadas en Tucumán para reprimir el levantamiento. Hacia finales de abril de 1781, la insurrección llegó a los pueblos de la Puna y las noticias de la rebelión estimularon en Salta y Jujuy la amenaza de levantamientos locales. ${ }^{6}$ Este proceso implicó consecuentemente una profunda depresión del mercado salteño: los repartimientos de mercancías eran abolidos en 1781, revirtiéndose la ampliación del mercado rural que había generado la legalización de los repartimientos en 1750 y su correlativa colocación de excedentes mediante la imposición compulsiva. ${ }^{7}$ Una vez sofocado el levantamiento, y ante un gran temor que aún recorría las calles y los caminos, ${ }^{8}$ hacia 1783 fue emplazado en Salta el Segundo Batallón del Regimiento de Saboya y el sistema defensivo local se complejizaba. ${ }^{9}$ Se modificaba así el paisaje demográfico salteño. El impacto fiscal, comercial y económico del estallido y de su represión fue, por lo tanto, contundente.

Un año más tarde, Salta experimentaría su definitivo reposicionamiento en el proceso de reconfiguración jurisdiccional que venía tomando impulso desde la creación del Virreinato del Río de la Plata: en 1784 quedaba definida la Intendencia de Salta del Tucumán, emplazándose una Caja principal en la ciudad de Salta — trasladada desde Jujuy- ${ }^{10}$ y cinco cajas subalternas (Santiago del Estero, Catamarca, Tucumán, Jujuy y, posteriormente, la Subdelegación de Puna). Un gobernador intendente, con sede en la ciudad, concentraría las causas de política, justicia, hacienda y guerra. ${ }^{11}$ Pero la centralización administrativa que la dinastía borbónica procuraba realizar con la redefinición intendencial del gobierno regional no logró, sin embargo,

6 Acevedo, La intendencia de Salta del Tucumán en el virreinato del Rio de la Plata, pp. 4350; Rees Jones, El Superintendente Manuel Ignacio Fernández (1778-1783). Las reformas borbónicas en el Virreinato de Buenos Aires, pp. 232-233. Al respecto, la configuración de una "frontera de guerra" en el chaco jujeño durante 1781 puede asimismo identificarse como un estímulo para el establecimiento de la Intendencia de Salta del Tucumán, tal como lo señala Cruz en "Notas para el estudio de las rebeliones indígenas".

7 Sara Mata, "Economía agraria y sociedad en los valles de Lerma y Calchaquí. Fines del siglo XVIII”, p. 61, explica que una vez atravesados los primeros momentos de la convulsión andina, se iniciaría una lenta recuperación con el reingreso de pueblos indígenas a la economía mercantil. Entre tanto, los "productos de origen europeo serán los únicos que finalmente sufrirán retracción en este mercado rural”.

8 Walker, De Túpac Amaru a Gamarra. Cusco y la formación del Perú Republicano. 17801840, passim.

9 Dicho batallón habría de permanecer en la ciudad hasta 1787, cuando es reemplazado por la Segunda Compañía del Segundo Batallón del Regimiento de Extremadura, que procedía de Lima. Véase Wayar, “Gastos militares en Salta. 1770-1809”, p. 125.

10 Acevedo, La intendencia de Salta del Tucumán en el virreinato del Rio de la Plata; Aramendi, "Burocracia y sociedad colonial. Las reformas borbónicas y su impacto en Salta (1750-1810)".

11 Lynch, Administración colonial española; Wayar, “Gastos militares en Salta. 1770-1809”, p. 122. 
incrementar la extracción de excedente fiscales desde el distrito salteño hacia las arcas porteñas: antes bien, desde 1784 Salta logra retener proporciones crecientes de sus excedentes fiscales, en cuyo manejo se incrementaba correlativamente la participación de comerciantes locales y regionales. ${ }^{12}$

Tanto la crisis de 1780 como el cambio institucional de 1784 desplegaron, por lo tanto, procesos con incidencia sobre distintos segmentos de la economía salteña. El crédito escriturado notarialmente permite advertir sus respectivos impactos, en la medida en que anudaba buena parte de las transacciones que daban vida al comercio salteño. Y el rol de la confianza en este punto resulta medular toda vez que la misma, tal como lo señalasen Barriera y Tarragó, representaba para el compromiso mercantil lo que el juramento representaba para la prueba jurídica: "es su garante, más allá del efectivo funcionamiento de la garantía". ${ }^{13}$ De manera que los modos de articular económicamente la confianza cambian y se instituyen de modos heterogéneos ante coyunturas oscilantes que estimulan a la incertidumbre, tal como se observará más adelante.

\section{EL CRÉDITO NOTARIAL EN SALTA DURANTE UN PERÍODO DE CONVULSIONES}

El trabajo de Sara Mata ${ }^{14}$ logró reconstruir las características estructurales del crédito mercantil salteño durante el último tercio del siglo XVIII y comienzos del XIX. Su abordaje sobre las escrituras de obligación notarialmente protocolizadas en Salta, agrupadas durante cuatro sexenios (1770-1775, 1780-1785, 1790-1795 y 1800-1805) permitió conocer, para cada uno de esos períodos: las garantías exigidas, la naturaleza del objeto acreditado, el cumplimiento de las obligaciones, los plazos e intereses, la procedencia y el destino regional de las transacciones. Ello habilitó la posibilidad de comprender la gravitación del comercio mular en la economía de Salta, la "monopolización del comercio mular alcanzado por comerciantes residentes o vecinos de otras ciudades del espacio andino", ${ }^{15}$ el rol de los efectos de Castilla como vehículo del asentamiento en Salta de comerciantes peninsulares habilitados por comerciantes porteños y, en suma, el modo en que el crédito anudaba los circuitos de mulas, plata y efectos de Castilla —así como de

2 Wayar, "Las remesas fiscales intra-coloniales. Una aproximación desde las cajas del Tucumán. 1759-1808”.

13 Barriera y Tarragó, "Elogio de la incertidumbre”, p. 192.

14 Mata, "El crédito mercantil. Salta a fines del siglo XVIII", passim.

15 Ídem, p. 170. 
otros bienes - para hacer de Salta un centro mercantil que vinculaba al noroeste con el espacio andino. ${ }^{16}$

Deteniéndonos ahora en la década que corre entre 1777 y 1786, período signado por las coyunturas descritas en el apartado anterior, y observando las escrituras de obligación rubricadas anualmente ante Antonio Gil Infante, único escribano salteño del período, la información desagregada por año nos permite una observación pormenorizada sobre algunas de aquellas variables.

Por lo tanto, se observan aquí las escrituras de obligación de pago. Dicho tipo documental constituía un contrato por el cual el deudor se obligaba a reintegrar a su acreedor un determinado monto dinerario en un plazo establecido. Conformaba por ello un negocio bilateral planteado en términos de obligación, cuyo objeto era una prestación patrimonial (la entrega de un bien por parte del acreedor, el reintegro de su valor monetario por parte del deudor). Por lo tanto, permitía a las partes formalizar legalmente toda transacción cuya retribución no fuese realizada al contado. ${ }^{17}$ Puesto que los negocios eran escriturados notarialmente en la medida en que alcanzaran ciertos criterios que lo ameritasen (tales como los montos involucrados, los riesgos asumidos y la distancia relacional entre las partes), ${ }^{18}$ estas transacciones representan un segmento del universo total posible. ${ }^{19}$ Pero por ello mismo, la escrituración notarial de los compromisos crediticios constituye una instancia que visibiliza transacciones de diversa naturaleza y permite reconstruir, consecuentemente, los circuitos que el crédito anudaba.

En Salta, entre 1777 y 1786 hemos relevado un total de 290 operaciones rubricadas como escrituras de obligación, las cuales canalizaron la suma de $\$ 1174474.38$.

Mijares Ramírez, Escribanos y escrituras públicas en el siglo XVI. El caso de la Ciudad de México, p. 165; Wasserman, Las obligaciones fundamentales. Crédito y consolidación económica durante el surgimiento de Buenos Aires.

18 Wasserman, Las obligaciones fundamentales. Crédito y consolidación económica durante el surgimiento de Buenos Aires.

19 Un análisis sobre las declaraciones testamentarias permite advertir que el 10\% de las deudas eran escrituradas notarialmente (frente a instrumentos privados y compromisos orales, principalmente). Ello responde al hecho de que las escrituras notariales eran los instrumentos preferentes para movilizar transacciones de valores elevados. De esta manera, el segmento de operaciones escrituradas notarialmente es representativo de las transacciones de elevado valor unitario, en contextos relacionales que no garantizan el cumplimiento de los compromisos sin apelación a la fuerza de la legalidad regia. Véase Wasserman, Las obligaciones fundamentales. Crédito y consolidación económica durante el surgimiento de Buenos Aires. 


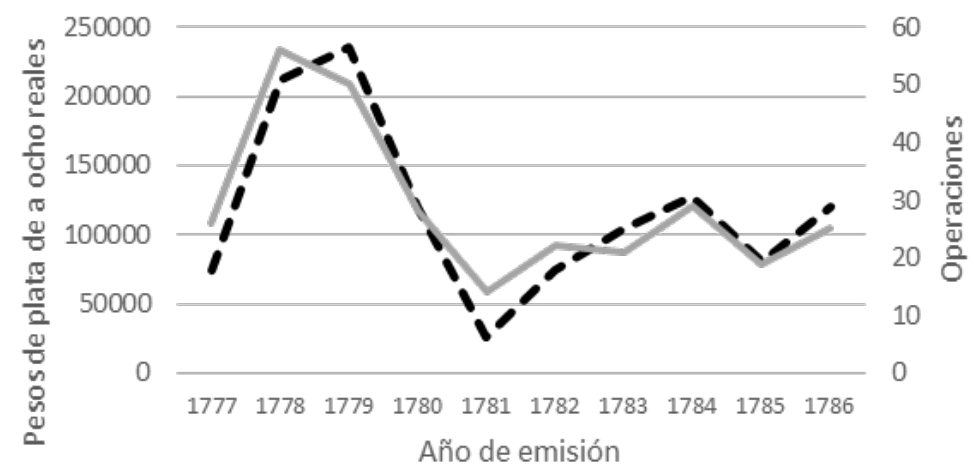

\section{- - Fondos Acreditados Operaciones}

Gráfica 1. Fondos acreditados y operaciones rubricadas. Salta 1777-1786.

Fuente: elaboración propia con base en el Archivo Histórico de Salta (en adelante, AHS), Protocolos notariales, Carpetas 14-39.

Nota: Las unidades monetarias han sido convertidas al sistema decimal siguiendo la fórmula propuesta por Jumar y Sandrín, en "El gasto público como dinamizador de la economía local. Río de la Plata, en la primera mitad del siglo XVIII": $n, 000=x+\frac{y}{8}+\frac{z}{272}$ (donde: $x$ representa pesos, $\mathrm{y}$ representa reales, $\mathrm{z}$ representa maravedís).

Como puede observarse, los volúmenes acreditados se desmoronan con el estallido de la revolución de Túpac Amaru. ${ }^{20}$ Puesto que también las sumas medias por operación experimentan un claro declive desde 1780, ello evidencia que, tal como hubiese sugerido $\mathrm{Mata}^{21}$ con base en las cifras estimadas por Sánchez Albornoz, la retracción del crédito vino acompañada del declive en los precios de las mulas como principal objeto de crédito (véase Tabla 1 y Gráfica 2).

20 Algunas obligaciones, en efecto, derivan del alcance de cuentas resultante de compañías que se deshacían ante la crisis comercial. Así, don Francisco Antonio de Bazagurren, residente en Salta, se obligaba a pagar a don José Javier de Anezábar, igualmente residente en la ciudad, \$2 700 en moneda corriente “por una liquidacion de quentas de hemos practicado de una compañía de comercio que hasta aquí teniamos pendiente”, de modo que daban por finalizada la empresa, "separandonos enteramente de ella”. El saldo se abonaría en Buenos Aires, en moneda doble, a los quince meses de la escrituración en Salta. AHS, Protocolos notariales, Carpeta 15, f. 33r, 31 de mayo de 1781.

21 Mata, "Economía agraria y sociedad en los valles de Lerma y Calchaquí. Fines del siglo XVIII”, pp. 75 y ss. 
Tabla 1

Objeto de crédito. Salta, 1777-1786

\begin{tabular}{lc}
\hline \multicolumn{1}{c}{ Objeto de crédito } & Participación \\
\hline Mulas y burros & $44.54 \%$ \\
Efectos de Castilla & $28.94 \%$ \\
Crédito monetario & $20.59 \%$ \\
Renovación de deudas previas & $3.22 \%$ \\
Efectos de la tierra & $2.24 \%$ \\
Esclavos & $0.33 \%$ \\
Inmuebles rurales & $0.13 \%$ \\
\hline & Total general \\
\hline
\end{tabular}

Fuente: véase Gráfica 1.

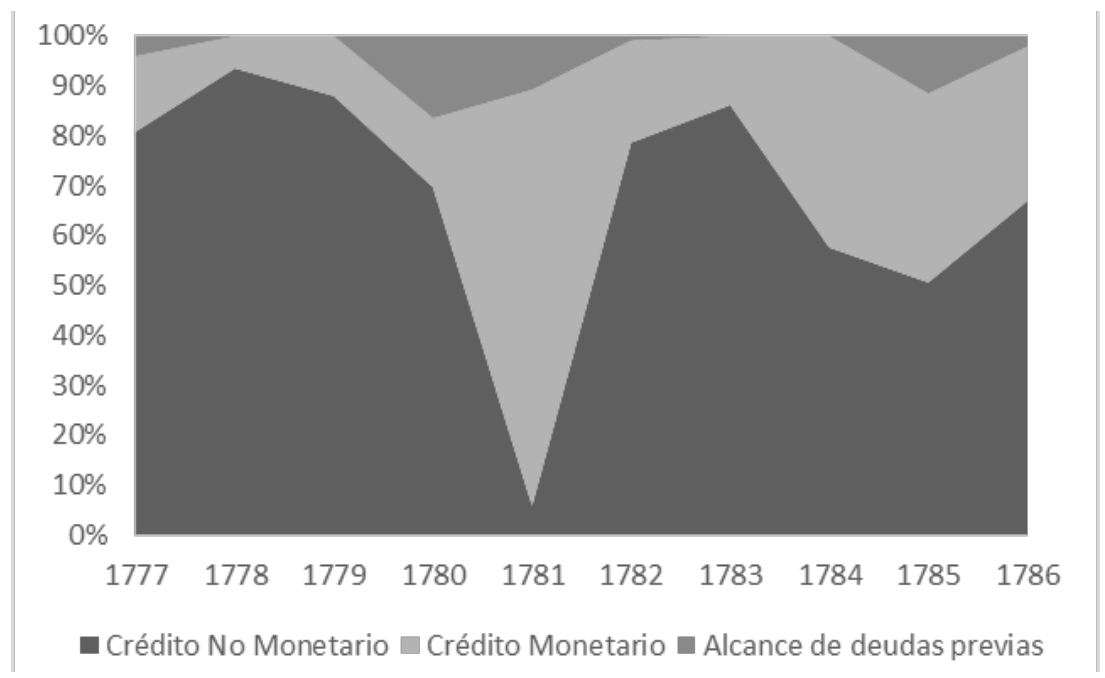

Gráfica 2. Objeto de crédito. Salta, 1777-1786.

Fuente: véase Gráfica 1.

En efecto, la participación del comercio mular en las transacciones crediticias rubricadas durante este período en Salta disminuye a su mínima expresión en 1781, cuando el mayor porcentaje de las pocas operaciones concertadas consiste en anticipos monetarios (Gráfica 3). 


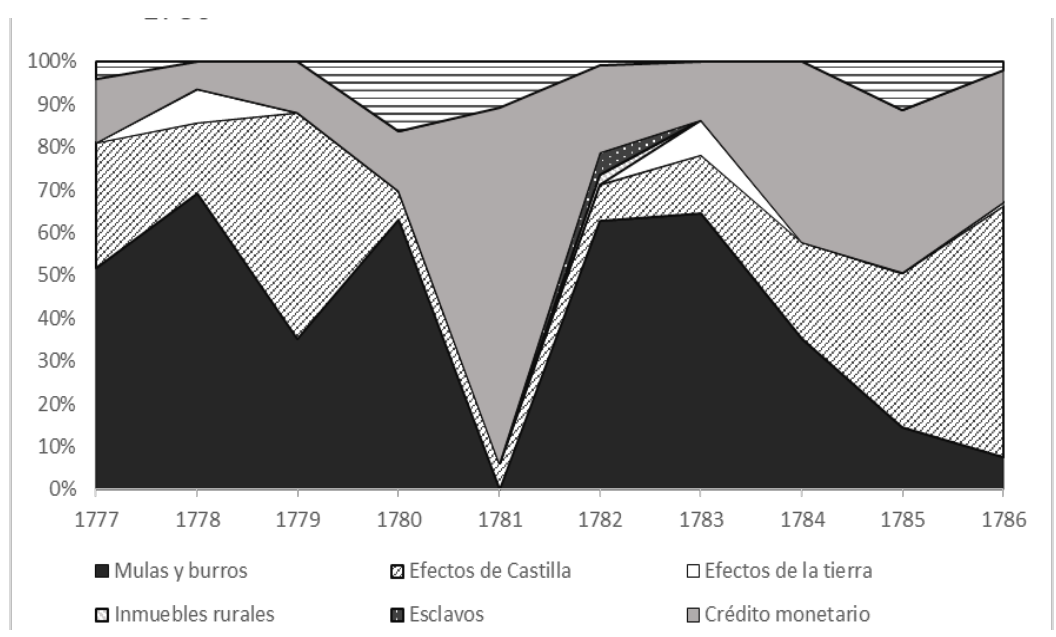

Gráfica 3. Objeto de crédito (desagregado). Salta, 1777-1786.

Fuente: véase Gráfica 1.

El inicio del período intendencial pareciera, en este sentido, haber estimulado la reincorporación de los efectos de Castilla en unos intercambios a crédito que comenzaban a recomponerse. ${ }^{22}$ Si bien los comerciantes salteños habrían ido acaparando la habilitación de tropas de mulas con efectos de Castilla, es probable que buena parte de esos productos de ultramar expresase asimismo una mayor presencia indirecta de representantes del comercio bonaerense, ${ }^{23}$ con lo cual la reconfiguración institucional de la jurisdicción habría estrechado el enlace comercial entre el mercado salteño y un jerarquizado puerto de Buenos Aires (en el Anexo I se ofrece una cartografía reticular para visualizar la cambiante participación de las regiones que se enlazaban mediante las escrituras de obligación rubricadas en Salta). ${ }^{24}$

22 Ya en 1778 el vecino salteño don Lorenzo Pérez se obligaba por la cuantiosa suma de \$9 437.37 a favor de don Francisco de La Torre, vecino de Buenos Aires, "procedidos de una memoria o facturas de efectos de castilla que a mi satisfaccion y contento me ha entregado a esta ciudad, al principal costo de la de Buenos Ayres, para conducirlos y entregarlos en la Villa Imperial del Potosi”. AHS, Protocolos notariales, Carpeta 15, f. 101r, 9 de abril de 1778.

23 Mata, "El crédito mercantil. Salta a fines del siglo XVIII”, p. 165.

24 Si bien es preciso atender a las propias dinámicas que articularon los mercados próximos a Salta frente a este proceso de crisis y cambio institucional, la virtual desaparición de escrituras de obligación rubricadas entre actores salteños y agentes de mercados cercanos puede estar dando cuenta no sólo de una retracción de estos últimos frente a la coyuntura, sino 
Entre tanto, la estipulación del reintegro pareciera haber respondido igualmente a las expectativas en el horizonte de corto plazo: aunque más del $70 \%$ del valor acreditado en todos los años se ofrecía contra el compromiso de devolver moneda corriente, la incertidumbre de 1781 por la crisis comercial derivada del levantamiento tupamarista, así como las expectativas por la reconfiguración intendencial en 1784, condujeron a incrementar la proporción de valor acreditado contra promesa de reintegro en moneda doble - es decir, piezas de alto valor nominal cuyo uso solía restringirse al comercio de larga distancia- (Gráfica 4).

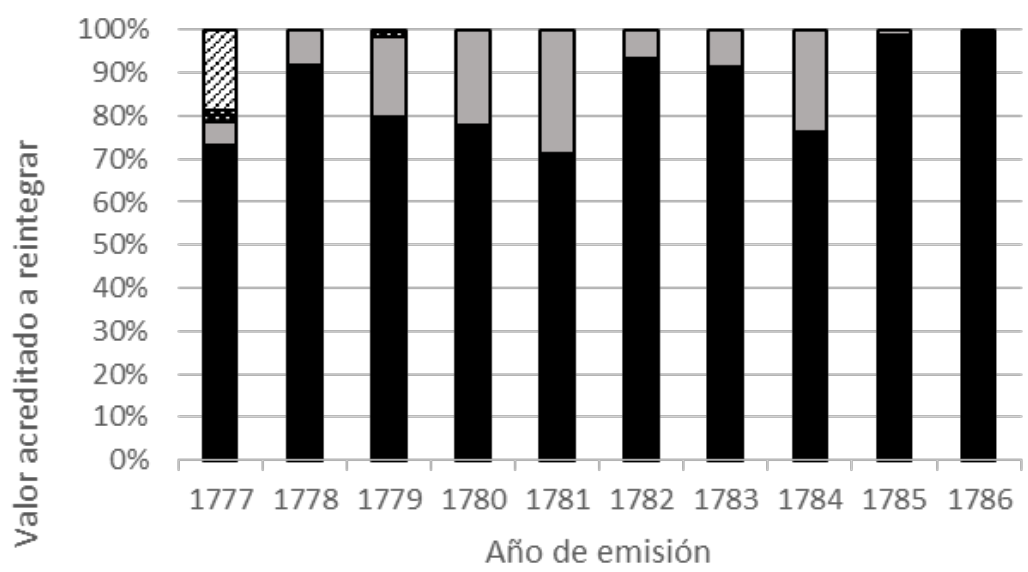

Moneda corriente $\square$ Moneda doble Telas o lanas $\mathbf{m}$ Ganado en pie

Gráfica 4. Estipulación de reintegro en escrituras de obligación. Salta, 1777-1786.

Fuente: véase Gráfica 1.

Pero la obligación de pago podía emplearse, asimismo, como medio para la cancelación de otros compromisos por parte de su acreedor, quien podía cederla como activo para saldar sus respectivas obligaciones pasivas, contribuyendo así al desarrollo de un mercado secundario en el cual el instrumento

asimismo de una concentración del comercio en manos de aquellos que logaban sortearla (de manera que los actores jujeños, por caso, continuarían participando tras el quiebre de 1781-1783); a ello deberá agregarse un factor explicativo que abordaremos en un siguiente apartado: la disminución de la densidad de las redes de crédito observadas. 
comenzaba a desprenderse de la obligación que lo había creado originalmente, práctica presente estructuralmente y ya desde el siglo anterior en la economía del antiguo Tucumán. ${ }^{25}$ Evaluando el porcentaje de obligaciones canceladas cuyo reintegro era cobrado no por su acreedor nominal, sino por un cesionario - quien había recibido el instrumento en calidad de pago por otras transacciones de parte del acreedor nominal — es visible que la práctica de lanzar a la circulación estos instrumentos resultaba habitual.

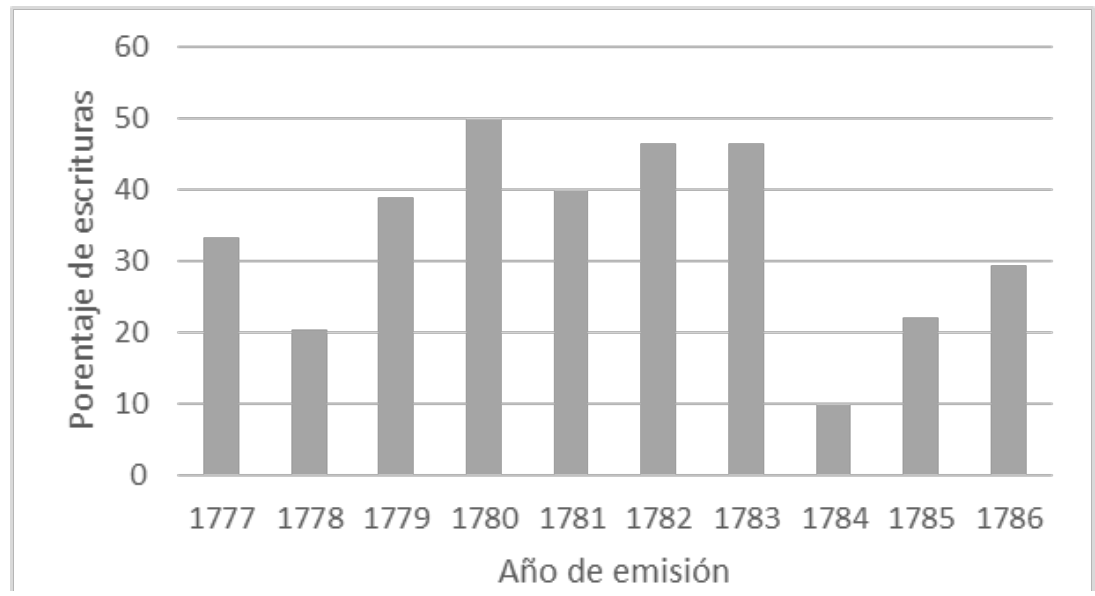

Gráfica 5. Porcentaje de obligaciones canceladas que fueron cedidas como medio de pago.

Fuente: véase Gráfica 1.

En este punto, el levantamiento de Túpac Amaru no parece haber tenido un impacto significativo sobre la puesta en circulación de obligaciones emitidas durante el proceso de conflictividad, a diferencia de lo que ocurre desde el establecimiento de Salta como cabecera intendencial (1784), lo cual sugiere que la reactivación de los circuitos por los que discurría el crédito notarial volvían a nutrirse de una liquidez monetaria que volvió prescindible la apelación a las escrituras como medio de pago. Una creciente liquidez derivada de la capacidad que adquirió Salta desde 1784 para retener en su jurisdicción (de la cual ahora era cabecera) una mayor proporción de sus excedentes fiscales; puesto que los comerciantes locales y regionales partici- 
paban protagónicamente de la redistribución de esos excedentes, su retención en Salta nutría de moneda a su mercado. ${ }^{26}$

Considerando entonces que toda una cadena de pagos podía llegar a desplegarse con base en los compromisos crediticios así originados (como lo muestra la Gráfica 5), este segmento de intercambios resultaba sensible a las diferentes alteraciones coyunturales del período. En efecto, los términos del intercambio sostenido con base en el crédito se trastocaban ante situaciones que implicaban el incremento de la incertidumbre. ${ }^{27} \mathrm{Y}$ esto es visible en el caso salteño, en el cual esos riesgos eran afrontados, en parte, mediante el requisito de garantías y la aplicación de intereses que procurasen transformar a la incertidumbre en un riesgo mensurable $y$, entonces, materialmente compensable.

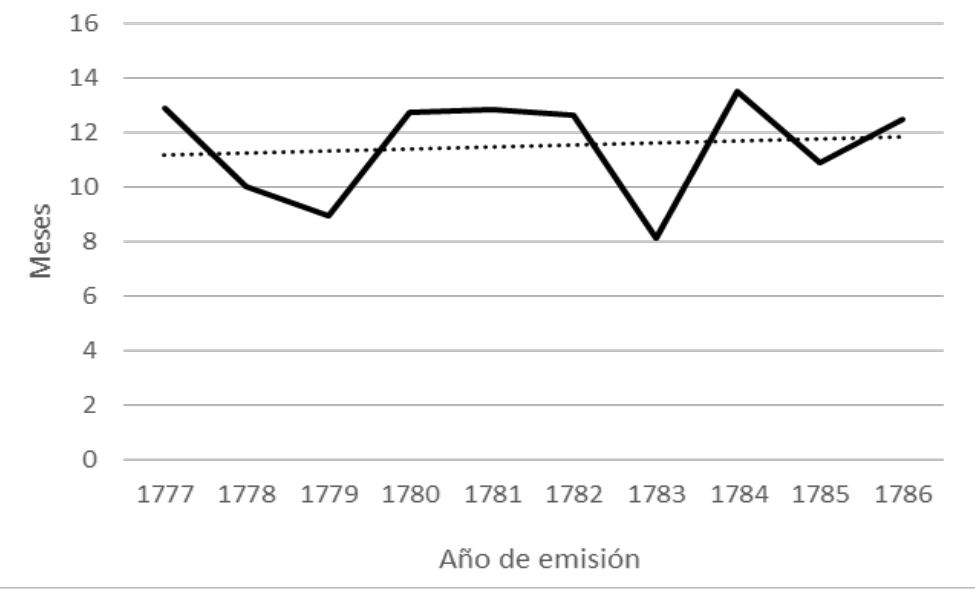

Gráfica 6. Plazo de reintegro estipulado en obligaciones de pago. Salta, 1786-1777 (promedio anual).

Fuente: véase Gráfica 1.

Por empezar, la morosidad en los reintegros constituía un primer indicador tangible del incremento del riesgo de cumplimiento: si el plazo de reinmán. 1759-1808”.

27 Wasserman, Las obligaciones fundamentales. Crédito y consolidación económica durante el surgimiento de Buenos Aires. 
tegro estipulado contractualmente promediaba los 12 meses $^{28}$ (véase Gráfica 6), el reintegro efectivo o porcentaje de escrituras canceladas pudo sostenerse sólo en base a un incremento de una morosidad con los cortocircuitos derivados de la revuelta, morosidad que sólo disminuye desde 1784 (Gráfica 7), cuando Salta como cabecera de Intendencia se vuelve capaz de retener recursos fiscales y aumentar la liquidez de los comerciantes participantes en el manejo de los mismos. ${ }^{29}$

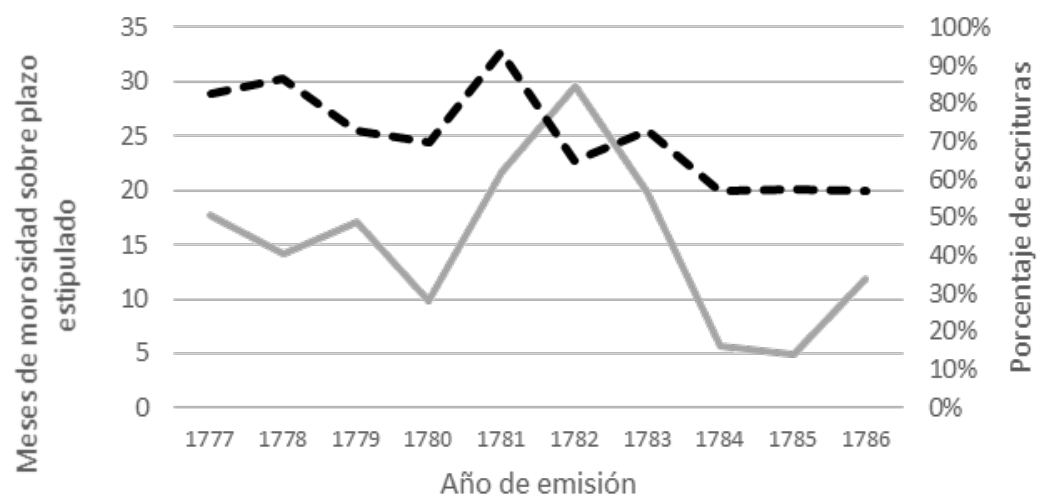

\section{- Morosidad sobre plazo estipulado, en meses (eje izquierdo) - Crédito cancelado (eje derecho)}

Gráfica 7. Cancelación y morosidad.

Fuente: véase Gráfica 1.

Correlativamente, el incremento de los riesgos en los circuitos implicó, desde 1781, el refuerzo de las garantías especiales aplicadas. Si el instru-

28 Desde luego, algunas operaciones condicionaban el reintegro a plazos definidos por otras variables. Así, el vecino salteño don Lorenzo Gómez se obligaba a reintegrar a su coterráneo don Sinforoso Josep de Rioja la suma de \$8 432.25 derivados de distintos efectos de Castilla, comprometiéndose a reembolsar “qinientos pesos para proximo situado que baje del Potosi a Buenos Ayres; otros qinientos pesos en el transcurso del presente año para alimentos de su familia” y, por en última instancia, "el resto dentro de diez y ocho meses contados desde ezta fecha en adelante”. AHS, Protocolos notariales, Carpeta 15, f. 85v, 18 de marzo de 1779 .

29 Wayar, "Las remesas fiscales intra-coloniales. Una aproximación desde las cajas del Tucumán. 1759-1808”. 
mento notarial ya implicaba una prueba ejecutable y, con ello, una garantía jurídicamente válida sobre los compromisos asumidos por sujetos no necesariamente inscritos en círculos de proximidad relacional, ello conducía a que las obligaciones de pago de todos los períodos estudiados se encontrasen mayoritariamente respaldadas por una garantía material endeble, consistente en la cláusula de obligación general de bienes o garantía general, según la cual el deudor comprometía su "persona y bienes habidos y por haber". Ante diferentes situaciones, era por lo tanto preciso agregar garantías especiales, ${ }^{30}$ en las que se señalasen expresamente ciertos bienes o respaldos materiales que quedaban hipotecados para satisfacer el pago en caso de incumplimiento al plazo convenido.

Tabla 2

Garantías ofrecidas. Escrituras de obligación, Salta 1777-1786

\begin{tabular}{lc}
\hline $\begin{array}{l}\text { I. Garantía general } \\
\text { II. Garantía hipotecaria }\end{array}$ & $86.55 \%$ \\
\hline \multicolumn{1}{c}{ Tipo de garantías hipotecarias } & $13.45 \%$ \\
\hline Inmueble urbano & $56.41 \%$ \\
Inmueble rural & $25.64 \%$ \\
Escrituras de crédito a favor & $5.13 \%$ \\
Esclavos & $5.13 \%$ \\
Mulas y burros & $5.13 \%$ \\
Mercadería & $2.56 \%$ \\
\hline
\end{tabular}

Fuente: véase Gráfica 1.

Asimismo, la aplicación de interés resultaba una compensación al riesgo, y si bien no está explicitado en la totalidad de las escrituras recabadas, es visible la aplicación de un interés que oscilaba entre el $5 \%$ y el 6\%, "según práctica y estilo del comercio”, tal como lo señalase Antonio Gil al obligarse 
por la suma de \$3 841.5 a favor de Fermín de la Sierra Pico como garantía por la entrega de 591 mulas. $^{31}$

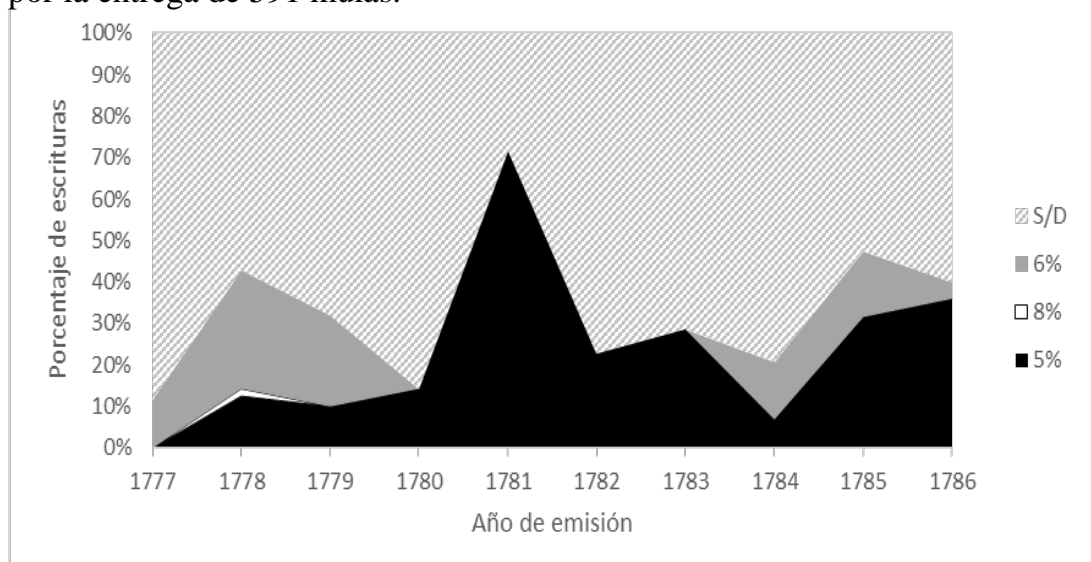

Gráfica 8. Tasas de interés anual aplicadas en escrituras de obligación. Salta, 1786. Fuente: véase Gráfica I.

De este modo, es claro que aquel incremento de la morosidad desde el estallido de la rebelión conllevó correlativamente un incremento de la apelación a garantías especiales y a la aplicación de tasas de interés definidas contractualmente, como puede observarse en la Gráfica 9. De igual modo, se advierte una disminución en la aplicación de interés y en la recurrencia a garantías hipotecarias cuando desde 1784 la morosidad disminuye.

En suma, la evolución de estas principales variables permite observar tres claros subperíodos en el crédito salteño a lo largo de esta década: 17771780, 1781-1783 y 1784-1786. Entre 1777 y 1780, los fondos acreditados y el volumen de transacciones escrituradas alcanzan niveles que no se replicarán posteriormente; el crédito se encontraba protagonizado por la entrega para comercialización de mulas y burros, así como de los efectos de Castilla; la morosidad se encontraba disminuyendo y la tasa de escrituras reintegradas se mantenía relativamente estable en niveles elevados, que promediaban el $70 \%$ de obligaciones canceladas; tasas de interés del $6 \%$ anual llegan a aplicarse sobre el $40 \%$ de las escrituras emitidas, sin una mayor apelación a

31 AHS, Protocolos notariales, Carpeta 18, f26r, 18 de abril de 1777. Véase asimismo, para una perspectiva hispanoamericana, Torres, “Tasas de interés y desempeño económico: el crédito comercial en Santafé de Bogotá, 1760-1810”, passim. 
garantías especiales. El panorama se revierte entre 1781 y 1783, cuando los fondos acreditados y el volumen de transacciones conocen un piso que expresa la crisis comercial derivada del levantamiento tupamarista; las operaciones pasan a estar protagonizadas por el crédito monetario, expresando la acumulación de metálico que no encontraba salida en el intercambio comercial y que era consecuentemente volcado en el mercado crediticio (hasta que en 1783 comience a reactivarse la circulación de mulas); la morosidad se dispara y la tasa de obligaciones reintegradas disminuye correlativamente; y si bien la tasa de interés concertada disminuye del $6 \%$ al $5 \%$ anual, se aplica sobre una mayor cantidad de escrituras emitidas (que llegan a representar el 70\%); de igual modo, se incrementa la apelación a garantías hipotecarias que respalden unos compromisos crediticios más arriesgados. Entre 1784 y 1786 los fondos acreditados y la dinámica de transacciones comienzan a recuperarse, una vez que el nivel de los precios salteños se estabiliza; ${ }^{32}$ avanza nuevamente el crédito mercantil en efectos de Castilla, y la liquidez pareciera recomponerse al observarse la disminución del empleo de escrituras de obligación como medio de pago; la morosidad disminuye pronunciadamente expresando una recomposición de los circuitos, si bien todavía las obligaciones reintegradas siguen sin superar el 60\% de las emitidas; y aunque la tasa de interés vuelve a subir al 6\%, disminuye la proporción de escrituras sobre las que se aplica, evidenciando criterios selectivos en función de aspectos que no necesariamente se derivan de la oferta de crédito ni de los riesgos del camino sino, probablemente, de la proximidad o de la distancia relacional entre las contrapartes, tal como también pareciera explicitarlo la apelación a garantías especiales sigue un mismo patrón que la aplicación de interés.

32 Esa estabilización se condice con un proceso en el cual el nivel de precios de Salta comienza a converger con el de las otras ciudades del espacio, como San Luis, Mendoza, Santa Fe y Corrientes, tal como se demuestra en Djenderedjian y Martirén, "Los precios de los bienes en el Virreinato del Río de la Plata y el carácter de la economía colonial. Una aproximación a partir de los aforos de Alcabalas (1782-1810)”. 


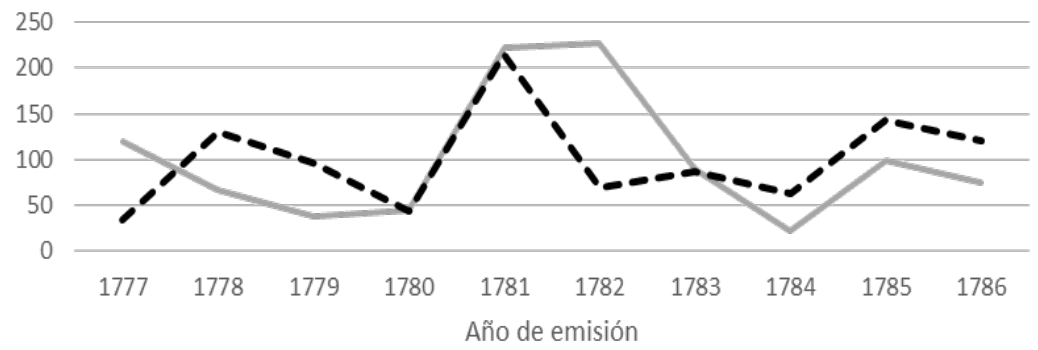

\section{_ Aplicación garantías especiales _ _ Aplicación de interés}

Gráfica 9. Aplicación de garantías especiales y de interés de pago. Salta, 1777-1786 (promedio=100).

Fuente: véase Gráfica 1.

\section{VARIABLES RELACIONALES Y DISTRIBUCIÓN: LA CONFIGURACIÓN DE LA INTERACCIÓN CREDITICIA SALTEÑA}

Si las variables desagregadas de los contratos permiten trazar una evolución clara del crédito durante este período y observar las alternancias que experimenta ante las distintas coyunturas, algunas variables estructurales sobre la interacción de los actores crediticios permiten comprender otras facetas que también dan cuenta de modos de afrontar los riesgos.

En este sentido, el análisis de la red resultante de escrituras de obligación de pago es revelador. Tratándose de una configuración de relaciones direccionadas (en donde el dinero, los bienes y los servicios acreditados siguen un sentido inverso al que siguen las obligaciones resultantes), la densidad de la red constituye una categoría analítica propicia para conocer el nivel general de integración entre sus nodos (en este caso, acreedores y deudores), calculado como la proporción de nexos realmente existentes sobre la totalidad de nexos posibles. A mayor grado de densidad, la red encuentra una mayor conexión interna que permite, consecuentemente, una circulación informacional que disminuye la asimetría de información y, por lo tanto, aminora el costo de transacción resultante en operaciones crediticias gracias a mecanismos reputacionales de sanción al incumplimiento. Correlativamente, menores grados de densidad aumentan el riesgo de oportunismo. ${ }^{33}$ En la 
dimensión relacional de las transacciones existe, por lo tanto, un dispositivo institucional con capacidad de regulación.

En este sentido, el análisis sobre la evolución de la densidad de la red de obligaciones de pago salteñas entre 1777 y 1786 demuestra que, tras el estallido de la revolución tupamarista, desde 1781 la densidad de la red disminuye, en un movimiento correlativo con el aumento de la morosidad en el pago de las obligaciones concertadas ese año (véase Gráfica 10 y Anexo II). Cuando la morosidad disminuya desde 1784 —año que recuerda al estable-

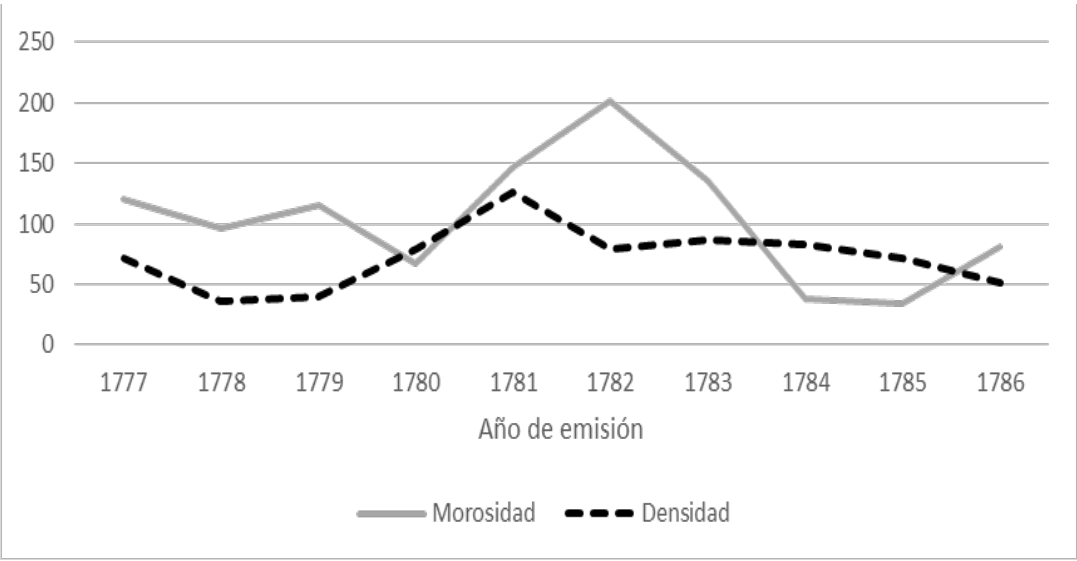

Gráfica 10. Morosidad y densidad de la red de obligaciones de pago. Salta, 1777-1786 (promedio= 100).

Fuente: véase Gráfica 1.

cimiento de la Intendencia-, la red crediticia aún no habría vuelto a apoyarse en circuitos relacionales densamente integrados $-\mathrm{y}$ de ello da cuenta el

del intercambio mediante arreglos institucionales que, aun costosos, permitan reemplazar la eventual ausencia de confianza entre las partes. Granovetter, "Economic Action and Social Structure: The Problem of Embeddedness”, p. 58, ha señalado, al respecto, que son las relaciones sociales efectivamente desplegadas entre los actores (antes que los arreglos institucionales o una moralidad generalizada) las principales responsables en la producción de confianza en la vida económica, aun cuando las redes de relaciones interpersonales no resulten suficientes por sí mismas para garantizar una conducta confiable en las partes. Por lo tanto, una medición sobre la densidad de la red resultante de las transacciones crediticias escrituradas como obligaciones de pago, ofrece una aproximación al grado con el que están integrados los actores participantes y la potencial eficacia que tendría, consecuentemente, la imposición de barreras a la entrada como resultado de sanciones al incumplimiento basadas en la reputación. 
incremento que se observaba en la aplicación de interés y de garantías especiales-. Esta constatación viene a sugerir que el crédito salteño, aun el escriturado notarialmente, se veía regulado por sanciones reputacionales que reforzaban el cumplimiento de los compromisos con mayor eficacia que las sanciones legales; ${ }^{34}$ ante la desarticulación temporaria de la red con el estallido de la revolución tupamarista, los contratiempos del circuito comercial se conjugaron con una disminución de la densidad reticular, que retroalimentaba la morosidad al disminuir el costo de oportunidad de faltar a los compromisos crediticios.

Considerando entonces que el circuito del crédito notarial salteño se encontraba fuertemente regulado por sanciones reputacionales que reforzaban el cumplimiento de los compromisos, es comprensible que la concentración de los fondos entre los deudores fuese más elevada que entre los acreedores: contarán con mayores fondos acreditables aquellos potenciales tomadores con mejor crédito personal.

La ratio entre el $20 \%$ de los deudores que mayores fondos recibió y el $20 \%$ de quienes menores fondos recibieron en el período 1777-1780 demuestra, en efecto, una mayor concentración entre los deudores que entre los acreedores (Gráfica 11). Y la distribución de fondos entre los deudores experimentó una más acusada concentración durante el período de crisis comercial derivada de la rebelión tupamarista, entre 1781 y 1783: una red menos densamente conectada entre acreedores y deudores durante dicho período, conjugada con riesgos acicateados en los caminos, condujo a concentrar el desembolso de los fondos en los pocos tomadores con crédito personal, reconocibles e identificables, como Pedro de Elexalde, quien concentró el $29.67 \%$ del valor acreditado mediante 10 escrituras entre 1781 y 1783 , habiendo igualmente participado como el principal tomador entre 1777 y 1780 con el $8.23 \%$ del valor acreditado mediante 12 escrituras.

Pedro de Elexalde arribó a la plaza salteña en el contexto de las inmigraciones de peninsulares a mediados del siglo XVIII. Avecindado en Salta hacia 1772, pronto consolidaría su pertenencia a la oligarquía local siendo designado por el Cabildo salteño como tesorero de las reducciones, ostentando el rango de sargento mayor $\mathrm{y}$, en 1773 , la vara de alcalde ordinario. Al igual que sus pares Juan Antonio Moldes o Manuel Antonio Boedo, acompañó

34 Ello se condice con un modo de minimizar los riesgos crediticios mediante la construcción de una "recíproca necesidad de las partes en el marco de un funcionamiento que excediera lo inmediato”. Barriera y Tarragó, "Elogio de la incertidumbre. La construcción de la confianza: entre la previsión y el desamparo (Santa Fe, Gobernación del Río de la Plata, siglo XVIII)", p. 191. 
este rápido ascenso social con una acelerada consolidación económica. ${ }^{35}$ Así, ya en marzo 1770 era apoderado por el comerciante salteño Francisco Gómez de Santibáñez para comercializar tropas de mulas en Perú ${ }^{36}$ y al mes siguiente incorporaría la representación de Joseph de Alvarado para la comercialización de efectos. ${ }^{37}$ Su capacidad para articular económicamente estos circuitos regionales lo condujo a formar una compañía con el salteño Juan Francisco de Ibarra ese mismo año de $1770^{38}$ y a constituirse, hacia 1780, como uno de los hombres con mayor inversión en el comercio mular salteño, invirtiendo en chacras y estancias para alcanzar protagonismo en el negocio de la invernada, tal como lo explica Mata. ${ }^{39}$

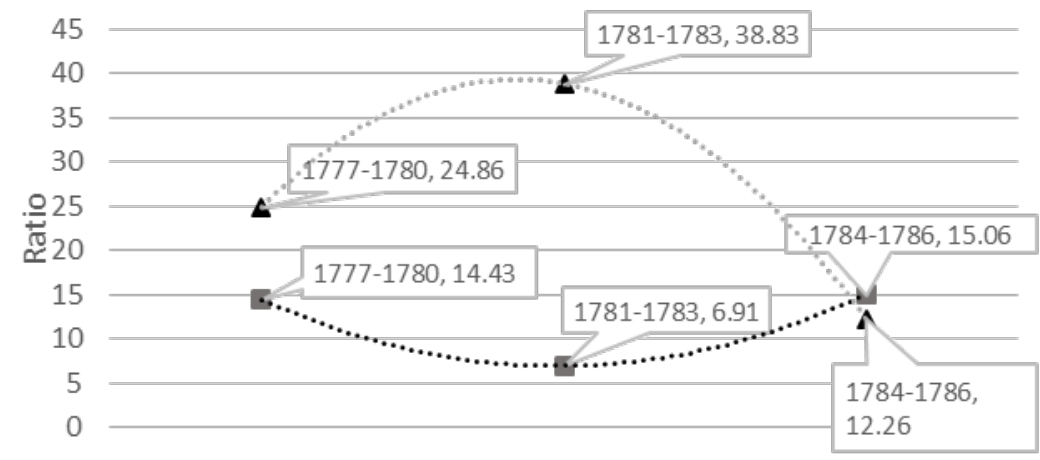

Ratio 20:20 Acreedores $\boldsymbol{\Delta}$ Ratio 20:20 Deudores

Gráfica 11. Desigualdad en la participación sobre los fondos acreditados es escrituras de obligación. Salta, 1777-1786.

Fuente: véase Gráfica 1.

Nota: la ratio 20:20 está calculada como la relación entre el promedio de fondos acreditados (acreedores) o tomados (deudores) por el grupo de actores que acumuló el primer $20 \%$ de fondos acreditados o tomados (primer quintil), por un lado, y el promedio de fondos acreditados o siglo XVIII".

38 AHS, Sección protocolos notariales, caja núm. 11, Folio núm. 235 v.

39 Mata, "Economía agraria y sociedad en los valles de Lerma y Calchaquí. Fines del siglo XVIII"; Mata, "Los comerciantes de Salta a fines del siglo XVIII", p. 196, 197 y ss. Véase, asimismo, Mata, Tierra y poder en Salta. 
tomados por el grupo de actores que acumuló el último 20\% de fondos acreditados o tomados (último quintil), por otro lado.

Tabla 3

Deudores que concentran el principal $20 \%$ del valor acreditado en cada período

\begin{tabular}{clc}
\hline \multirow{2}{*}{ Período } & \multicolumn{1}{c}{ Deudor } & $\begin{array}{c}\text { \% de valor recibido } \\
\text { durante el período }\end{array}$ \\
\hline \multirow{2}{*}{$1777-1780$} & Pedro de Elexalde & $8.23 \%$ \\
& Jose Robledo & $7.76 \%$ \\
& Benito de Allende & $5.99 \%$ \\
\hline \multirow{2}{*}{$1781-1783$} & Pedro de Elexalde & $29.67 \%$ \\
\hline \multirow{2}{*}{$1784-1786$} & Juan de Zenarruza & $10.12 \%$ \\
& Juan Carrillo y Albornoz & $7.38 \%$ \\
& Gaspar Saenz Bravo & $6.26 \%$ \\
\hline
\end{tabular}

Fuente: véase Gráfica 1.

Tabla 4

Acreedores que concentran el principal $20 \%$ del valor acreditado en cada período

\begin{tabular}{clc}
\hline \multirow{2}{*}{ Período } & \multicolumn{1}{c}{ Acreedor } & $\begin{array}{c}\text { \% de valor acreditado } \\
\text { durante el período }\end{array}$ \\
\hline \multirow{2}{*}{$1777-1780$} & Francisco Antonio Díaz & $6.87 \%$ \\
& Felipe Haedo & $5.27 \%$ \\
& Manuel Salvador Fernández & $4.62 \%$ \\
\multirow{2}{*}{$1781-1783$} & Gabriel de Torres & $4.30 \%$ \\
& Gregorio Guzmán & $8.61 \%$ \\
& José de Isosa & $6.87 \%$ \\
\multirow{2}{*}{$1784-1786$} & Estanislao Zamudio & $6.82 \%$ \\
& Manuel Antonio Tejada & $12.68 \%$ \\
& Miguel Francisco Gómez & $10.12 \%$ \\
\hline
\end{tabular}

Fuente: véase Gráfica 1.

El comienzo del período intendencial entre 1784 y 1786 viene a poner en evidencia que, aun con redes de crédito que no volvían a contar con elevada densidad, cierta democratización del crédito fue posible, al punto de revelarse menos concentrados los fondos entre los deudores que entre sus acreedores. De hecho, los principales acreedores de Salta concentraron menos 
acusadamente su participación, y de ello da cuenta el recambio de actores en el grupo de principales acreedores de cada período.

Francisco Antonio Díaz, principal acreedor durante 1777-1780, era un prolífico mercader avecindado en Córdoba, cuyo giro comercial se complementaba con la expansión sobre la campaña cordobesa gracias al aprovechamiento de coyunturas como la abierta por la expulsión de la Compañía de Jesús y la subsecuente venta de bienes de Temporalidades entre 1770 y $1780 .{ }^{40}$ Desde la década de 1760, Díaz anudaba los circuitos mercantiles entre Buenos Aires y Salta con transacciones de elevado monto. ${ }^{41}$ Como lo señala Aramendi, ${ }^{42}$ Díaz se encontraba íntimamente vinculado al comercio porteño, hecho que lo volvió un reconocido introductor de bienes de Castilla, negocio al que desde 1770 agregaría la inversión en el comercio mular. Su protagonismo entre los acreedores en Salta durante el período 1777-1780 responde, precisamente, al comercio mular: por caso, el 18 de julio de 1778 entregaba a un vecino salteño tropas de mula en consignación por la elevada suma de $\$ 44.147$, a reintegrarse en Salta en moneda corriente durante "todo el mes de marzo del año venidero de setenta y nuebe". ${ }^{43}$

La actividad económica de Gregorio Guzmán, el principal acreedor en Salta entre 1781 y 1783, se caracterizó por el desarrollo de vínculos comerciales con actores del mercado de Buenos Aires dedicados al tráfico ultramarino y a la redistribución regional de las importaciones. Así, Guzmán consolidó tratos con Tomás de Balanzategui, importador de esclavos asentado en Buenos Aires con gravitación medular en la estructura institucional del comercio porteño; ${ }^{44}$ por caso, en 1785 Guzmán se comprometía a reintegrar a Balanzategui la suma de \$2 380 procedentes "de varios efectos de castilla que me ha vendido al fiado”. ${ }^{45}$ De igual modo, en 1792 Guzmán se obligaría a reintegrar a Juan Bautista de Hecibia la suma de \$11 162.3 procedidos de

Punta, Córdoba borbónica. Persistencias coloniales en tiempo de reformas (1750-1800), pp. 76-78; Márquez, "Grupos de mercaderes cordobeses en el espacio peruano. La incidencia de las reformas borbónicas y las sublevaciones indígenas”, passim.

41 Por caso, participaba de una cuenta corriente que alcanzaba el valor de \$39630 con el prominente comerciante porteño Juan Esteban de Anchorena. Milletich, "La formación del capital de un comerciante porteño: Juan Esteban de Anchorena”, pp. 321-322.

42 Aramendi, “¿Poder local versus poder real? Conflictos entre el Cabildo de Córdoba y el Gobernador don Joaquín Espinosa y Dávalos”.

43 La obligación sería cancelada el 16 de junio de 1779, con tres meses de mora. AHS, Protocolos notariales, Carpeta 15, f. 188v, 18 de julio de 1778.

44 Balanzategui llegó a participar, en efecto, de los debates relativos a la interrupción del comercio derivado de la conflictividad bélica, firmando una petición dirigida a Belgrano para solicitar y obtener autorización para la navegación vía de Cabo de Hornos en la travesía a los puertos del Pacífico con protección de la Marina Real (Caula, 2011).

45 Caula, "Las configuraciones mercantiles a escala de imperio a finales del período colonial: pautas de comportamiento, circulación de recursos y experiencias". 
"efectos y géneros de Castilla de los que a su consignación le han vendido desde España”, ${ }^{46}$ evidenciando un incremento en el giro de Guzmán con Buenos Aires. Ello le permitió solidificar sus enlaces mercantiles con comerciantes salteños de la talla de Domingo Santibáñez y Domingo Antonio Patrón, quienes representaban en Salta a los mismos actores porteños a los que Guzmán representaba: Juan Bautista Hecibia y Tomás de Balanzategui. ${ }^{47}$

Un perfil similar ofrece el castellano Manuel Antonio Tejada, principal acreedor durante 1784-1786. Tejada también había arribado a Salta a mediados del siglo XVIII y, ya hacia 1773, es identificable su ejercicio comercial en la jurisdicción: ese año forma una compañía mercantil con Juan Antonio Moldes (con quien posteriormente reforzaría el enlace al casarse con su cuñada) para comercializar efectos de Castilla y aguardiente de España importados por Buenos Aires para su remisión a Potosí. ${ }^{48}$ Tejada desplegó vínculos con reconocidos actores del universo mercantil y político de Buenos Aires; así, sostuvo negocios y correspondencia comercial con Bernardo Sánchez Larrea, de quien había recibido la considerable suma de \$10 000 que Tejada destinó en parte a un préstamo al 15\% de interés anual a Cayetano Viniegra para la producción, invernada y comercio mular hacia el mercado potosino. ${ }^{49}$ Los enlaces con Buenos Aires y la financiación productiva permitieron a Tejada innovar en el patrón de comercialización: en junio de 1784 comenzaba a enviar cargas de lana de vicuña andina hacia Buenos Aires para su exportación a "los reinos de España y otras plazas europeas", 50 como volvería a hacerlo al año siguiente. ${ }^{51}$ No sorprende, por lo tanto, su desempeño en Salta como tesorero y alcalde ordinario de segundo voto.

De este modo, el perfil de los principales deudores y acreedores del período permite volver a corroborar que el comercio mular salteño estaba sostenido por prácticas crediticias que permitían su dinamización; pero también permite comprender que el establecimiento Salta como cabecera de la Intendencia coincidió con un fortalecimiento de los lazos que acreedores salteños

AHS, Registro judicial, juzgado de $1^{\circ}$ instancia en lo civil, expediente núm. 10, año 1792. Caula, "Las configuraciones mercantiles a escala de imperio a finales del período colonial: pautas de comportamiento, circulación de recursos y experiencias". AHS, Registro judicial, juzgado de $1^{\circ}$ instancia en lo civil, Expediente núm. 12, año: 1827. AHS, Registro judicial, juzgado de $1^{\circ}$ instancia en lo civil, Expediente núm. 12, año 1827. Sobre la trayectoria comercial de Cayetano Viniegra, y su participación en una trama de estancieros y comerciantes que trascendían a la jurisdicción salteña, véase Mata, "Los comerciantes de Salta a fines del siglo XVIII”, pp. 194 y ss.

AHS, Fondo Hacienda, Libro núm. 4.68, folio 81 v.

AHS, Fondo Hacienda, Libro núm. 468, folio 123r. 
sostenían con el vértice de Buenos Aires, retroalimentando su capacidad crediticia para revitalizar al comercio mular tras la inflexión de 1780.

\section{CONCLUSIONES}

La rebelión de 1780 representó un quiebre del comercio salteño con los mercados regionales, y las variables del crédito lo evidenciaban: desde 1781, a la caída en el volumen de transacciones crediticias y en los fondos acreditados le correspondía una mayor morosidad y una elevada falta de pago; y dada la desaceleración en la circulación mular, el metálico que no encontraba salida en ese intercambio mercantil pasó a protagonizar el objeto de crédito. Entre tanto, los riesgos expandieron la aplicación de tasa de interés y de garantías hipotecarias sobre una mayor proporción de contratos. Pero para afrontar los crecientes riesgos crediticios y reasegurar los compromisos, los actores apelaron a un mecanismo fundamental: circunscribir la circulación de los fondos entre aquellos actores reconocibles por su crédito personal. Si ello no es directamente visible a través de las cláusulas contractuales de las obligaciones de pago, sí puede visibilizarse mediante el análisis de la densidad o interconexión de la red que las escrituras configuraban: una mayor densidad contribuía a disminuir la asimetría en la información entre las contrapartes, pero también permitía implementar mecanismos de sanción reputacional que incrementaba el costo del incumplimiento. Ello se expresa en la continuidad de Pedro de Elexalde como principal tomador: si desde 1777 se constituía como principal deudor, su protagonismo perdurará más allá de la inflexión de 1780 dada su reputación crediticia.

Si desde 1783 comenzaba lentamente a reactivarse la circulación de mulas apoyada en el crédito, será desde 1784 que los fondos acreditados y la dinámica de transacciones comiencen a recuperarse, recomponiéndose asimismo, la liquidez tal como lo demuestra la disminución del empleo de escrituras de obligación como medio de pago, y la morosidad disminuye pronunciadamente - aun cuando las obligaciones reintegradas todavía no superan el 60\% de las emitidas-. Pero la recomposición de los circuitos se da en un contexto en el cual la densidad de la red crediticia disminuye: una trama más abierta o menos interconectada, con menor eficacia potencial de las sanciones reputacionales ante el incumplimiento de los compromisos, implicaba entonces mayores riesgos para aprovechar las nuevas oportu-

nidades que ofrecía este reanudamiento de los circuitos. Si bien el incremento de la tasa de interés al $6 \%$ y la aplicación de garantías especiales pueden dar cuenta de mecanismos implementados para afrontar ese riesgo persistente una vez reanudados los circuitos comerciales, éstos fueron sobrellevados mediante la apuesta a una nueva diversificación de las inversiones, expresa- 
da en la reincorporación incrementada de los efectos de Castilla como un rentable objeto de crédito y comercialización. Y ello fue posible sólo en la medida en que los acreedores salteños (primordialmente, consignatarios de partidas mercantiles para la redistribución) estrechasen sus enlaces con el rosario de economías regionales que conectaban con el Atlántico. La primacía de acreedores como Gregorio Guzmán o Manuel Antonio Tejada, estrechamente enlazados al comercio ultramarino a través de Buenos Aires, lo pone en evidencia.

De esta manera, las transacciones crediticias rubricadas como escrituras de obligación vienen a demostrar que el establecimiento de la Intendencia de Salta del Tucumán favoreció la integración de los mercados regionales, retroalimentando la gravitación del frente atlántico como fuente de crédito y dinamismo mercantil. Si los propósitos centralizadores borbónicos que esta reconfiguración jurisdiccional representaba no tuvieron efecto en términos fiscales - toda vez que desde 1784 proporciones crecientes de los excedentes fiscales de la Intendencia de Salta del Tucumán eran retenidos en las arcas salteñas-,${ }^{52}$ ello pudo constituir el costo fiscal de una mayor integración comercial, en la que no sólo comenzaban a converger precios, ${ }^{53}$ sino actores.

De este modo, sin haber subsumido fiscalmente la región salteña al epicentro rioplatense, el cambio institucional implicado en el establecimiento de la Intendencia de Salta del Tucumán fomentó un doble movimiento en la estructura comercial: mientras que el capital porteño avanzaba sobre el crédito salteño, los actores salteños avanzaban sobre los circuitos interregionales. El proceso de reformulaciones borbónicas pudo caracterizarse, entonces, por el fortalecimiento de la integración entre las economías regionales y los actores que las anudaban. Una integración necesaria para dotar de liquidez y crédito a unos circuitos que se recomponían.

\section{BIBLIOGRAFÍA}

Acevedo, E.O., La intendencia de Salta del Tucumán en el virreinato del Río de la Plata, Mendoza, Universidad Nacional de Cuyo-Facultad de Filosofía y Letras-Instituto de Historia, 1965.

52 Wayar, "Las remesas fiscales intra-coloniales. Una aproximación desde las cajas del Tucumán. 1759-1808”

53 Djenderedjian y Martirén, "Los precios de los bienes en el Virreinato del Río de la Plata y el carácter de la economía colonial. Una aproximación a partir de los aforos de Alcabalas (1782-1810)". 
Anachuri, M.G., "Créditos y fortunas: el caso de Juan Antonio Moldes en Salta de fines del siglo XVIII”, en América Latina en la Historia Económica, vol. 26, núm. 3, 2019, pp. 1-23. DOI: 10.18232/alhe.972.

Aramendi, B., “¿Poder local versus poder real? Conflictos entre el Cabildo de Córdoba y el Gobernador don Joaquín Espinosa y Dávalos”, en Andes, núm. 22, 2011.

, "Burocracia y sociedad colonial. Las reformas borbónicas y su impacto en Salta (1750-1810)”, en I Congreso Internacional de Estudios Latinoamericanos de Postgrado - I Encuentro Nacional de Cátedras de Historia de América, Tafí del Valle, Cátedras de Historia de América, FFyL, unT, 2015.

Assadourian, C.S., El sistema de la economía colonial. El mercado interior. Regiones y espacio económico, México, Nueva Imagen, 1983.

Barriera, D. y Tarragó, G., "Elogio de la incertidumbre. La construcción de la confianza: entre la previsión y el desamparo (Santa Fe, Gobernación del Río de la Plata, siglo XVIII)”, en Revista Historia, núm. 48, 2003, pp. 183-223.

Caula, E., "Las configuraciones mercantiles a escala de imperio a finales del período colonial: pautas de comportamiento, circulación de recursos y experiencias”, en Anuario del Instituto de Historia Argentina, núm. 11, 2011, pp. 151-180.

Clavero, B., "Hispanus fiscus, persona ficta. Concepción del sujeto político en el ius commune moderno", en Quaderni Fiorentini per la storia del pensiero giuridico moderno, 11-12, 1982-1983, pp. 95-167.

Cruz, E.N., "Notas para el estudio de las rebeliones indígenas a fines del período colonial en la frontera tucumana del Chaco (1781)”, en Anuario de Estudios Americanos, vol. 64, núm. 2, 2007, pp. 271-286. DOI: 10.3989/aeamer.2007.v64.i2.89.

Djenderedjian, J. y Martirén, J.L., “Los precios de los bienes en el Virreinato del Río de la Plata y el carácter de la economía colonial. Una aproximación a partir de los aforos de Alcabalas (1782-1810)", en XXV Jornadas de Historia Económica, Salta, Asociación Argentina de Historia Económica, 2016.

Garzón Maceda, C., Economía del Tucumán. Economía natural y economía monetaria. Siglos XVI-XVII-XVIII, Córdoba, Universidad Nacional de Córdoba, 1968.

Grafe, R. and Irigoin, A., "Bargaining for Absolutism. A Spanish Path to Empire and Nation Building”, en The Hispanic American Historical Review, vol. 88, núm. 2, 2008, pp. 173-209. DOI: 10.1215/00182168-2007-117.

Granovetter, M., "Economic Action and Social Structure: The Problem of Embeddedness”, en Granovetter, M. y Swedberg, R. (eds.), The Sociology of Economic Life, Colorado-Oxford, Westview Press, 2001.

Hodgson, G., "What are Institutions?", en Journal of Economics Issues, vol. 40, no. 1, 2006, pp. 1-25. DOI: 10.1080/00213624.2006.11506879.

Jumar, F. y Sandrín, M.E., "El gasto público como dinamizador de la economía local. Río de la Plata, en la primera mitad del siglo XVIII”, en Sánchez Santiró, E. 
(coord.), El gasto público en los imperios ibéricos, siglo XVIII, México, Instituto Mora-CONACyT, 2015, pp. 205-272.

Lynch, J., Administración colonial española, Buenos Aires, EUDEBA, 1962.

Márquez, M.V., "Grupos de mercaderes cordobeses en el espacio peruano. La incidencia de las reformas borbónicas y las sublevaciones indígenas”, en XXI Jornadas de Historia Económica, Buenos Aires, Asociación Argentina de Historia Económica, 2008.

Martínez López-Cano, M.P. La génesis del crédito colonial. Ciudad de México, siglo XVI, México, UNAM, 2001.

Mata, S., "Economía agraria y sociedad en los valles de Lerma y Calchaquí. Fines del siglo XVIII”, en Anuario del IEHS, VI, 1991, pp. 59-80.

, "Los comerciantes de Salta a fines del siglo XVIII", en Anuario, Escuela de Historia de la Facultad de Humanidades de la Universidad Nacional de Rosario, núm. 16, 1993-1994, pp. 189-211.

_ Americanos, vol. 53, núm. 2, 1996, pp. 147-171. DOI: 10.3989/aeamer.1996.v53.i2.419.

_ dencia, Salta, CEPIHA-Facultad de Humanidades-UNSa, 2005.

Mijares Ramírez, I., Escribanos y escrituras públicas en el siglo XVI. El caso de la Ciudad de México, México, Instituto de Investigaciones Históricas, UNAM, 1997.

Milletich, V., “La formación del capital de un comerciante porteño: Juan Esteban de Anchorena”, en Anuario del IEHS, XXI, 2006, pp. 311-330.

Punta, A. I., Córdoba borbónica. Persistencias coloniales en tiempo de reformas (1750-1800), Córdoba, UNC, 1997.

Rees Jones, R., El Superintendente Manuel Ignacio Fernández (1778-1783). Las reformas borbónicas en el Virreinato de Buenos Aires, Buenos Aires, Instituto de Investigaciones de Historia del Derecho, 1992.

Sánchez Santiró, E., "El orden jurídico de la fiscalidad en la Real Hacienda de Nueva España: un análisis a partir de la calidad, el estado y la clase de los contribuyentes”, en Espacio, Tiempo y Forma, serie IV, núm. 27, 2014, pp. 85-107. DOI: 10.5944/etfiv.27.2014.13702.

Schmit, R. e Irigoin, M.A. (eds.), La desintegración de la economía colonial: comercio y moneda en el interior del espacio colonial, 1800-1860, Buenos Aires, Biblos, 2003.

Scott, J., Social Network Analysis. A Handbook, London-Thousand Oaks-New Delhi, SAGE Publications, 2000.

Torres, J.V., “Tasas de interés y desempeño económico: el crédito comercial en Santafé de Bogotá, 1760-1810”, en América Latina en la Historia Económica, vol. 21, núm. 3, 2014, pp. 9-45. DOI: 10.18232/alhe.v21i3.577. 
Torres Sánchez, R., “Tejiendo una Hacienda Imperial. 'Unir los manejos de la Real Hacienda de España y América’ en el reinado de Carlos III”, en Bertrand, M. y Moutoukias, Z. (eds.), Cambio institucional y fiscalidad. Mundo hispánico, 1760-1850, Madrid, Casa de Velázquez, 2018, pp. 43-63.

Walker, Ch., De Túpac Amaru a Gamarra. Cusco y la formación del Perú Republicano. 1780-1840, Cusco, Centro de Estudios Bartolomé de las Casas, 1999.

Wasserman, M., Las obligaciones fundamentales. Crédito y consolidación económica durante el surgimiento de Buenos Aires, Buenos Aires, Prometeo, 2018. , “Gasto público y actividad económica en la Hispanoamérica de Antiguo Régimen: Buenos Aires en el siglo XVII. Una aproximación desde el Análisis de Redes Sociales”, en REDES. Revista Hispana para el Análisis de Redes Sociales, vol. 29, núm. 1, 2018, pp. 139-162. DOI: 10.5565/rev/redes.731.

Wayar, A., “Gastos militares en Salta. 1770-1809”, en López, C. y Mata, S. (comps.), Historia regional en perspectiva comparada, Salta, CEPIHA-UNSa-UNT, 2011, pp. 109-130.

_ _ "Las remesas fiscales intra-coloniales. Una aproximación desde las cajas del Tucumán. 1759-1808”, en Jornadas uruguayas de Historia Económica, Montevideo, Asociación Uruguaya de Historia Económica, 2011.

Williamson, O., Markets and Hierarchies, New York, Free Press, 1975. 
Anexo I

\section{GEOGRAFÍA CAMBIANTE DE LAS OBLIGACIONES ESCRITURADAS EN SALTA}

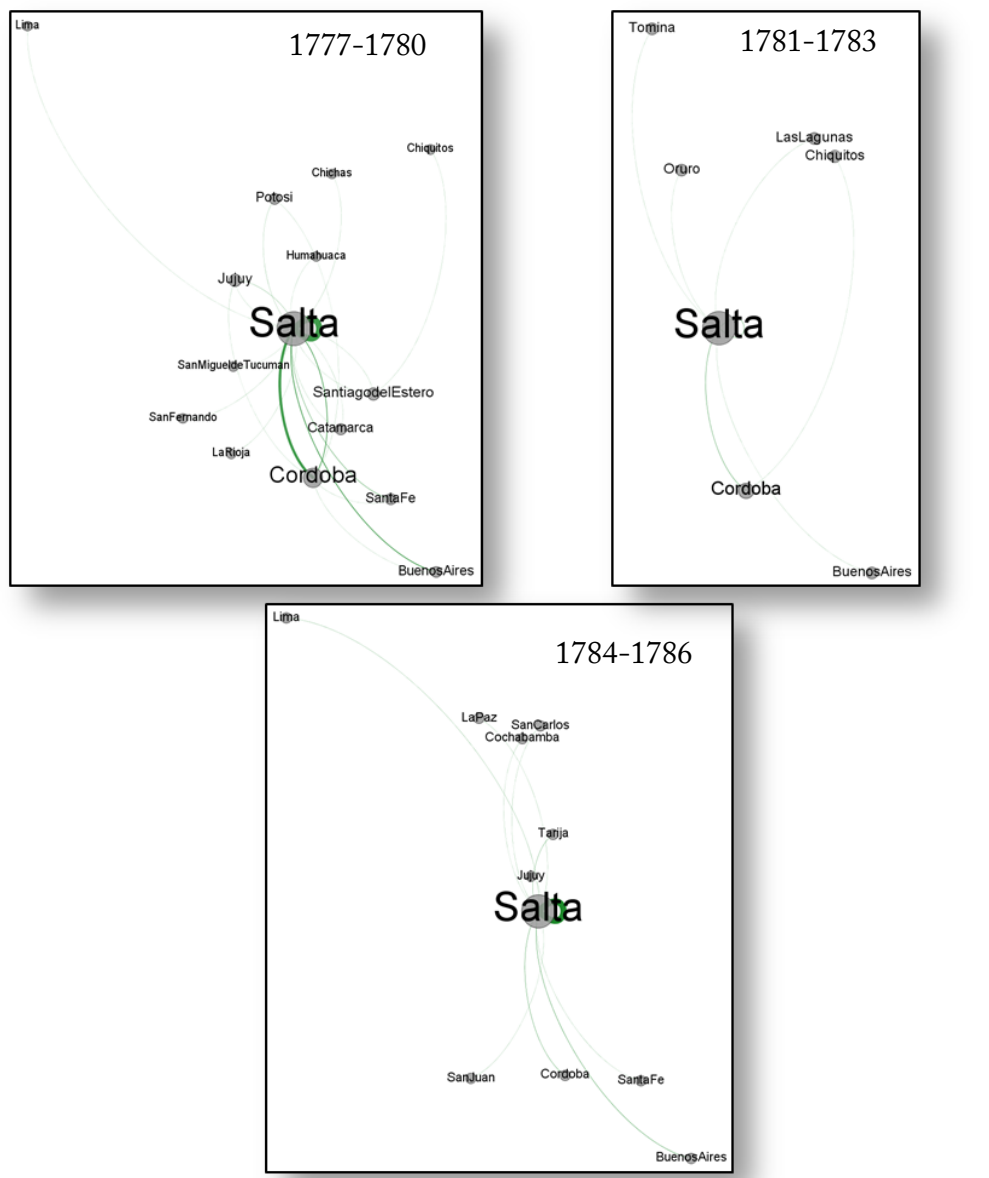

Fuente: $\quad$ Elaboración propia en Gephi 0.8.2beta con base en AHS, Protocolos notariales, Carpetas 14-39.

Nota: $\quad$ El tamaño de cada nodo está definido por el grado de enlaces, que modela la cantidad de escrituras de obligación que tienen a la localidad por fuente o destino del financiamiento. El grosor de los enlaces modela la frecuencia de contacto entre los nodos ponderada por las sumas transferidas. 


\section{ANEXO II}

Densidad de la red resultante de escrituras de obligación. Salta, 1777-1786

\begin{tabular}{cc}
\hline Año de emisión & Densidad de la red de escrituras de obligación de pago \\
\hline 1777 & 0.018 \\
1778 & 0.009 \\
1779 & 0.01 \\
1780 & 0.02 \\
1781 & 0.032 \\
1782 & 0.02 \\
1783 & 0.022 \\
1784 & 0.021 \\
1785 & 0.018 \\
1786 & 0.013 \\
\hline
\end{tabular}

Fuente: Elaboración propia en Gephi 0.8.2beta, con base en AHS, Protocolos notariales, Carpetas 14-39. Para una estructura direccionada como la del crédito notariado, en la que el sentido seguido por el flujo de los valores es en pocas situaciones recíproco y da lugar por lo tanto a lazos habitualmente asimétricos, la densidad ha de medirse como $\frac{l}{n(n-1)}$ donde $l$ equivale al número de lazos realmente existentes y $n$ al número de actores involucrados en la estructura direccionada (Scott, Social Network Analysis. A Handbook, pp. 69-73). El valor de esta medida puede oscilar entre 0 y 1 : alcanzando este último valor, la estructura está completamente interconectada. Los valores arrojados por los distintos períodos corroboran una trama con densidad considerablemente baja, escasamente interconectada, que se constata en la escasa interconexión entre los tomadores del mismo acreedor (Wasserman, “Gasto público y actividad económica en la Hispanoamérica de Antiguo Régimen: Buenos Aires en el siglo XVII. Una aproximación desde el Análisis de Redes Sociales”). 